\title{
Eating Disorders among Indian Adolescents
}

\author{
Shanthi S Babu ${ }^{1}$, Amitha Rao Aroor ${ }^{2}$
}

\begin{abstract}
Objective: To assess and compare the prevalence and risk for eating disorders (ED) among middle and late adolescents in India.

Materials and Methods: A prospective study conducted among 1855 adolescents of age group 14 years to 19 years from four schools and three colleges in Mangalore city. A standardized structured questionnaire was used to evaluate the subjects' attitude toward and preoccupation with food, dieting, eating, physical appearance, and personal control over eating. Eating Attitudes Test questionnaire (EAT-26), consisting of 26 questions that assess the symptoms and concerns that are characteristic of eating disorders and four additional questions to asses weight control behavior patterns adapted. Participants who scored 20 and above on EAT were considered to have eating disorder that would require professional attention.

Results: 1855 students participated in the study and completed the self-report EAT-26. Among the study participants, $47.3 \%$ were in mid-adolescence and $52.7 \%$ in late-adolescent age group respectively. $26.7 \%$ of participants scored 20 and above; scores attained were correlated with the behavioral patterns adapted which was found to be statistically significant, indicating a high risk for development of eating disorders among adolescents. Higher prevalence of eating disorder was noted in those with increased BMI ( $p$-value $<0.0001$ ) but age and gender did not have a significant influence.

Conclusion: Eating disorders and subthreshold eating conditions are prevalent in sample of Indian adolescents and were strongly associated with psychological, behavioral and socioenvironmental domains, which show the necessity of initiating routine screening programs and intervention programs to control eating disorders among Indian adolescents. Further evaluation, counseling and follow-up with a qualified professional is essential to rule out any underlying cause for eating disorder.
\end{abstract}

Keywords: Eating disorder, Adolescents, Eating attitude test

${ }^{1}$ Junior Resident, ${ }^{2}$ Professor, A.J. Institute of Medical Sciences \& Research Centre, Mangalore.

Correspondence: Dr. Shanthi S Babu, Junior Resident, A.J. Institute of Medical Sciences \& Research Centre, Mangalore.

E-mail Id: ss4shan@gmail.com

Orcid Id: http://orcid.org/0000-0002-2329-7519

How to cite this article: Babu SS, Aroor AR. Eating Disorders among Indian Adolescents. Ind J Youth Adol Health 2017; 4(1): 11-15.

Digital Object Identifier (DOI): https://doi.org/10.24321/2349.2880.201703

ISSN: $2349-2880$ 


\section{Introduction}

Adolescence is the period characterized by peak growth and physical maturation. Healthy diet helps teenagers reach complete growth potential, increase health and wellbeing and decrease the risk of chronic diseases in senior ages. ${ }^{1}$

Eating disorder (EDs) is a complex illness that has impact on both physical and socio-emotional health of young people, and contributes to significant morbidity. Dieting behaviors and body image concerns are common in adolescence and it can be challenging to identify those at the extreme end of this spectrum who are at risk of an eating disorder. ${ }^{2}$

The alarming increase in the number of teenagers with eating disorder underscores the need to promote research on the underlying causes, and to identify highrisk subpopulations in need of effective targeted treatment. $^{3}$

In the context of increasing rates of obesity, there has been increased focus on weight reduction, dieting and physical activity in the general community. Young people who diet moderately are six times more likely to develop an eating disorder. While only a small proportion of those who diet develop an eating disorder, dieting is considered as a major risk factor. ${ }^{4}$

Assessing abnormal nutritional attitudes in normal population is essential to supervise and follow up the change in trend for preventive planning and healthcare. Epidemiologic studies about eating disorder and its types among teenagers have been performed mainly in southern Europe and the northern American populations and fewer studies performed in other areas as Greece, Turkey, Israel and South America. Further study on different populations is needed to fill the present scientific gap. ${ }^{5}$

Screening for eating disorder is an essential step in the process of early identification and intervention. Furthermore, it improves prognosis, but presentation of $E D$ is often cryptic.

In the past few years, several effective screening tools have been designed for the assessment of symptoms and behavior presented by patients with eating disorders. Self-report questionnaires and semistructured interviews are the two main assessment modalities. There are also other measures related to preoccupation with body image, dietary consumption, amongst others, as well as measures related to comorbidity (depression, anxiety, etc.). ${ }^{14}$
Self-report questionnaires measure symptoms and risk behavior of eating disorders, but not as diagnostic tools. They also aid in early identification of subjects who require medical attention. ${ }^{6}$

\section{Objective}

To assess and compare the prevalence and risk for eating disorders among middle and late adolescents in India.

\section{Materials and Methods}

In this cross-sectional analytical study, the prevalence of eating disorder and its relation with individual variables was explored among 1855 middle and late adolescents of age group 14-19 years in Mangalore city in October 2015.

Sample size of 1395 was calculated using Eq. (1) considering a power of $80 \%$, a relative precision of $2 \%$, confidence level of $99 \%$ and prevalence of eating disorders to be $26 \% .{ }^{13}$ Finally, sample size was increased to 1590 considering $20 \%$ non-response.

$$
\text { 1) } \quad N=Z_{1-\frac{\alpha}{2}}^{2} \times \frac{\mathrm{P}(1-\mathrm{P})}{d^{2}}
$$

Mangalore city with a population of $488,968^{21}$ is one of the important educational centers in Karnataka with 108 colleges and 116 high schools. Based on convenience factor, four schools and three colleges were selected and the questionnaires were distributed. After permission from the regional committee of research ethics of AJ Institute of Medical Sciences and initial introduction, we explained our objectives to the research units and asked their willingness to participate in our research. Assent was taken from parents and consent from the participants. Assent and consent forms were attached with the questionnaires distributed and explained that the obtained information would be kept confidential. A total of 1855 completed forms were collected and assessed.

A self-report standardized questionnaire, EAT-26 (Eating Attitudes Test-26) developed by Garner et $\mathrm{al}^{6}$ was employed in this study for the assessment of attitudinal and behavioral dimensions relevant to eating disorders and administered to all enrolled participants. The questionnaire had three parts - the first part for sociodemographic variables, second comprised of Eating Attitude Test (EAT) to assess the abnormalities in eating behavior and the third part had questions to assess psychological variables and risk factors. The EAT-26 has 
been widely used and has been translated into many different languages over the past 30 years. ${ }^{6}$

Participants who scored 20 and above on EAT were considered to have eating disorder that would require professional attention. Scores attained were correlated with the BMI scores to interpret the final result.

The obtained data was analyzed using SPSS (Version 17.0, Chicago, IL, USA). Statistical significance was checked using the Chi-square test and Student's t test. $95 \%$ confidence limits were set so that if $p$ value was less than 0.05 , the difference was considered significant.

\section{Results}

In our study, among the 1855 students who participated in the study, $47.2 \%(n=878)$ were middle adolescents and $52.8 \%(n=977)$ were late adolescents, among whom $48 \%(n=891)$ were males and $52 \%(n=964)$ were females.

When interpreted on BMI chart, majority were in normal range $(56.4 \%, n=10647)$, followed by undernutrition $(32.5 \%, n=604)$, overweight $(9.9 \%, n=183)$ and obesity $(1.1 \%, n=21)$ in decreasing order.

Figure 1 shows the risk of ED with the EAT-26 criteria regarding body mass index (BMI), which shows that there is a significant correlation between the two parameters; higher prevalence of ED was noted in those with increased BMI ( $p$-value $<0.0001)$. 81\% $(n=18)$ of children in obese category were noted to have ED.

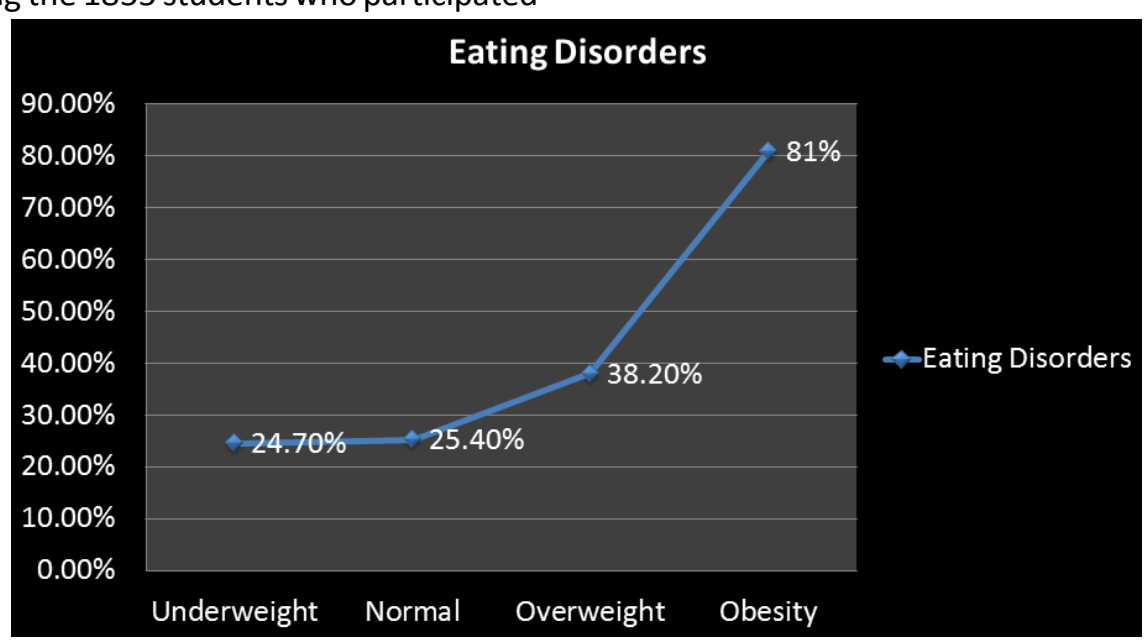

Figure 1.Correlation between Eating Disorder and BMI

Table 1.Correlation between Demographic Variables with EAT Score

\begin{tabular}{|l|c|c|c|}
\hline \multicolumn{1}{|c|}{ FACTOR } & $\begin{array}{c}\text { Normal } \\
\text { EAT Score (<2) }\end{array}$ & $\begin{array}{c}\text { At Risk } \\
\text { ( EAT score } \geq 20)\end{array}$ & P- Value \\
\hline $\begin{array}{l}\text { BMI } \\
\text { Underweight \& } \\
\text { Normal } \\
\text { Overweight \& } \\
\text { Obese }\end{array}$ & $1234(74.7 \%)$ & $417(25.3 \%)$ & $<0.0001$ \\
\hline $\begin{array}{l}\text { BEHAVIOR } \\
\text { Negative }\end{array}$ & $125(61.3 \%)$ & $79(38.7 \%)$ & \\
$\begin{array}{l}\text { Positive } \\
\text { GENDER }\end{array}$ & $1086(78.1 \%)$ & $305(21.9 \%)$ & $<0.0001$ \\
$\begin{array}{l}\text { Male } \\
\text { Female }\end{array}$ & $273(58.8 \%)$ & $191(41.2 \%)$ & 0.217 \\
\hline $\begin{array}{l}\text { AGE } \\
\text { Middle Adolescents } \\
\text { Late Adolescents }\end{array}$ & $641(71.9 \%)$ & $250(28.1 \%)$ & \\
\hline
\end{tabular}

The study showed significant association between BMI and behavior patterns with development of eating disorders (Table 1). Children with higher BMI had adjusted odds ratio (OR) of 1.75 showing that they are
1.75 times at higher risk for developing ED. Similarly, those with abnormal behavior score are 2.45 times more likely to develop ED compared to those with normal behavior (Table 2). 
Table 2.Relationship between Eating Disorder and Demographic Variables

\begin{tabular}{|c|c|c|c|c|}
\hline VARIABLES & OR & Lower & Upper & P-Value \\
\hline UNADJUSTED & & & & \\
\hline BMI & 1.87 & 1.382 & 2.572 & $<0.0001$ \\
\hline Behavior & 2.491 & 1.991 & 3.118 & $<0.0001$ \\
\hline Age & 1.020 & 0.83 & 1.25 & 0.853 \\
\hline Sex & .878 & 0.715 & 1.079 & 0.217 \\
\hline BDJSTED & & & & \\
\hline Behavior & 1.755 & 1.286 & 2.396 & $<0.0001$ \\
\hline Age & 1.035 & 1.956 & 3.071 & $<0.0001$ \\
\hline Sex & 0.910 & 0.736 & 1.124 & 0.217 \\
\hline
\end{tabular}

Among the study population, $26.7 \%(n=496)$ scored $\geq 20$, meaning they were at risk for eating disorder.

The number of adolescents at risk for eating disorder were found to be similar when compared between early and late adolescent age group signifying that age did not have significant influence on eating disorder.

According to multiple logistic regression analysis, behavior and BMI significantly predicted the prevalence of risk for development of eating disorders.

\section{Discussion}

The primary finding of this study, the prevalence of eating disorder symptoms and disordered eating attitudes and behaviors in a sample of adolescents came out to be $26.7 \%$. This is comparable with reports from other investigators, ${ }^{(7-13)}$ who had used EAT and reported prevalence of disordered eating attitudes and behaviors to be between 16.5 and $27 \%$ in different study groups.

Adolescence is a period when specific types of problems including body dissatisfaction are more likely to arise than in other periods of development. These problems may result in eating disorders. On the eating attitude test, $26.8 \%$ of Indian teenagers $(25.5 \%$ female and $28.1 \%$ male) showed a propensity for eating disorder behavior.

Similar studies were performed in different continents which can be compared with the present study. The reported percentage of girls at risk of eating disorders in Saudi Arabia was $24.6 \%,{ }^{18} 29.4 \%$ in Oman, ${ }^{15} 23.4 \%$ in the $\mathrm{UAE}^{19}$ and $15.76 \%$ in Brazil. $^{16}$ The reported percentage of boys at risk of eating disorders in Spain was $8 \%{ }^{17}$ and in Oman $36.4 \% .{ }^{15}$ In comparison to the above studies, our study showed no significant statistical variation among both sex for the prevalence of eating disorder.
These results provide important information for clinical practice. The results of this study suggest that the prevalence of disordered eating and unhealthy weightcontrol behaviors in adolescent population is high, with a multitude of psycho-social factors contributing to their vulnerability. There is a need for longitudinal study in Indian setup to isolate the risk factors and evaluate the possible relationship between demanding environments and psychosomatic vulnerability. In the interim, our findings convey that eating disorders comprise a significant health concern among adolescents, and health programs should be included for educational services on school campuses in an effort to alleviate potential risk factors and unhealthy behaviors and attitudes.

All persons who have direct contact with students, especially parents and teachers, should be trained by nurses or healthcare providers in schools about issues related to ED. This training can include basic nutritional needs, effects of restrictive diets, side effects of purging methods, the symptoms of ED, people at risk of ED and boosting self-esteem, because self-esteem can prevent body image distortion.

This study has a few limitations. Firstly, sampling may not be representative of all of the adolescent Indian population. Another limitation is the use of anonymous self-report questionnaires to collect data, relying upon the honesty of the students. It is possible that biased answers were collected, in which case the prevalence rate may have been under- or overestimated.

Despite these limitations, this study provided key information concerning the epidemiology of eating disorders among Indian adolescents. More epidemiological studies on ED in India are recommended due to scarce performed investigations. In addition, preventive school-based studies are needed. 


\section{Conclusion}

Eating disorders and sub-threshold eating conditions are prevalent in sample of Indian adolescents and were strongly associated with psychological, behavioral and socio-environmental domains. This shows the necessity of initiating routine screening programs and intervention programs to control eating disorders among Indian adolescents. Further evaluation, counseling and follow-up with a qualified professional is essential to rule out any underlying cause for eating disorder.

\section{Conflict of Interest: Nil}

\section{References}

1. Shannon C, Story M, Fulkerson JA et al. Factors in the school cafeteria influencing food choices by high school students. J Sch Health 2002; 2(6): 29-34.

2. Yeo M, Hughes E. Eating disorders: Early detection in clinical practice. Australian Family Physician March 2011; 40(3): 108-11.

3. Mateos-Padorno $\mathrm{C}$ et al. Analysis of eating disorders among 12-17 year old adolescents in the island of Gran Canaria. Eat Weight Disorder 2010; 15(3): 19094.

4. Patton GC, Selzer R, Coffey C et al. Onset of adolescent eating disorders: population based cohort study over 3 years. BMJ 1999; 318: 765-68.

5. Makino $M$, Hashizume $M$, Tsuboi $K$ et al. Comparative study of attitudes to eating between male and female students in the People's Republic of China. Eat Weight Disord 2013; 11(3): 111-17.

6. Garner DM. Eating Attitude TestC (EAT-26): Scoring and Interpretation. (cited May 15, 2016). Available from: http://www.eat-26.com/Docs/EAT-26Intpret Scoring-Test-3-20-10.pdf

7. Anstine D, Grinenko D. Rapid screening for disordered eating in college-aged females in the primary care setting. J Adolesc Health 2000; 26(5): 338-42.

8. Jones JM, Bennett S, Olmsted MP et al. Disordered eating attitudes and behaviors in teenaged girls: $A$ school based study. CMAJ. 2001; 165(5): 547-52.

9. Goyal RK, Shah VN, Saboo BD et al. Prevalence of overweight and obesity in Indian adolescent school going children: Its relationship with socioeconomic status and associated lifestyle factors. J Assoc Physicians India 2010; 58: 151-53

10. Palma-Coca O, Hernández-Serrato MI, Villalobos-
Hernández A et al. Association of socioeconomic status, problem behaviors, and disordered eating in Mexican adolescents: Results of the Mexican National Health and Nutrition Survey 2006. J Adolesc Health 2011; 49(4): 400-06.

11. Swanson SA, Crow SJ, Le Grange D et al. Prevalence and correlates of eating disorders in adolescents: Results from the national comorbidity survey replication adolescent supplement. Arch Gen Psychiatry 2011; 68(7): 714-23.

12. Prisco AP, Araújo TM, Almeida MM et al. Prevalence of eating disorders in urban workers in a city of the northeast of Brazil. Cien Saude Colet 2013; 18(4): 1109-18.

13. Maryam Rauof, Hossein Ebrahimi, Mohammad Asghari Jafarabadi et al. Prevalence of eating disorders among adolescents in the northwest of Iran. Iran Red Crescent Med J 2015 Oct; 17(10): e19331.

14. Clinical Practice Guidelines for Eating Disorder 17476.

15. Al-Adawi S, Dorvlo AS, Burke DT et al. Presence and severity of anorexia and bulimia among male and female Omani and non-Omani adolescents. J Am Acad Child Adolesc Psychiatry 2002; 41(9): 1124-30.

16. Vilela JE, Lamounier JA, Dellaretti Filho MA et al. Eating disorders in school children. J Pediatr (Rio J) 2004; 80(1): 49-54.

17. Rodriguez-Cano T, Beato-Fernandez L, BelmonteLlario A. New contributions to the prevalence of eating disorders in Spanish adolescents: Detection of false negatives. Eur Psychiatry 2005; 20(2): 17338.

18. Al-Subaie A, Al-Shammari S, Bamgboye E et al. Validity of the Arabic version of the eating attitude test. Int J Eat Disord 1996; 20(3): 321-24.

19. Eapen V, Mabrouk AA, Bin-Othman S. Disordered eating attitudes and symptomatology among adolescent girls in the United Arab Emirates. Eat Behav 2006; 7(1): 53-60.

20. Karnataka's tier II cities miss out on boom. Deccan Herald Oct 24, 2011. Archived from the original on 1 Mar 2012. Retrieved 26 Oct 2011.

21. Mangalore City Census 2011 data (cited Oct 15, 2016). Available from: http://www.census 2011. co.in/census/city/451-mangalore.html.

$$
\begin{aligned}
& \text { Date of Submission: } 28^{\text {th }} \text { Dec. } 2016 \\
& \text { Date of Acceptance: } 23^{\text {rd }} \text { Mar. } 2017
\end{aligned}
$$

